\title{
Fóruns participativos, controle democrático e a qualidade da democracia no Rio Grande do Sul: a experiência do governo Olívio Dutra (1999-2002)
}

\author{
Cláudia Feres Faria
}

Universidade Federal de Minas Gerais

\section{Resumo}

Este artigo pretende analisar, a partir de uma experiência recente de governo no âmbito estadual - a gestão de Olívio Dutra (1999-2002) no Rio Grande do Sul -, o impacto da implantação de um conjunto de fóruns participativos na relação entre os poderes executivo e legislativo neste estado, bem como no aprimoramento dos mecanismos de controle público sobre os mesmos. O objetivo é, especificamente, analisar os efeitos dos fóruns participativos promovidos pelo Orçamento Participativo estadual (OP.RS) uma iniciativa do executivo estadual - e pelo Fórum Democrático - uma iniciativa do legislativo estadual - sobre a prática democrática no Rio Grande do Sul.

Palavras-chave: orçamento participativo estadual, fóruns participativos, controle democrático, relação executivo e legislativo, Rio Grande do Sul

\begin{abstract}
This article intends to analyze the impact of a set of participatory forums at state level in the relation between executive and Legislative powers at Rio Grande do Sul, as well as in the improvement of the mechanisms of public control on the same ones. The objective is, therefore, to analyze the participatory effects of the forums promoted by Participatory Budgeting (OP-RS) - a state Executive initiative - and by the Democratic Forum - a state Legislative initiative - on democratic practice in the Rio Grande do Sul.
\end{abstract}

Key words: participatory budgeting at state level, participatory forums, democratic control, executive and legislative relation, Rio Grande do Sul 
FARIA, C. F. Fóruns participativos, controle democrático e a qualidade da democracia...

Introdução ${ }^{1}$

O sistema político brasileiro, quando confrontado com certas democracias maduras, aparece, segundo Abranches (1988), como um caso singular, uma vez que apresenta um arranjo político-institucional caracterizado pelo presidencialismo, pelo federalismo, pelo bicameralismo, pelo multipartidarismo, pela representação proporcional e por um executivo organizado com base em grandes coalizões. As conseqüências deste arranjo singular incidem diretamente sobre o processo de consolidação da democracia brasileira, tornando o nosso sistema político mais instável (ABRANCHES, 1988, p. 27).

$\mathrm{O}$ argumento da instabilidade, imputado principalmente ao "presidencialismo de coalizão", vem sendo relativizado pela literatura sobre o tema. Valendo-se da presença de uma série de mecanismos institucionais que promovem a preponderância dos interesses do poder executivo sobre os do poder legislativo, vários autores colocarão em xeque tal argumento (FIGUEIREDO e LIMONGI, 1999; SANTOS, 1997; MELO, 2005). Prerrogativas exclusivas do executivo como, por exemplo, seus poderes legislativos através do uso de Medidas Provisórias, do veto e da capacidade de garantir a votação urgente de determinados projetos de leis, dentre outros instrumentos procedimentais para controlar a agenda legislativa, garatem a ascendência do executivo sobre o legislativo e, conseqüentemente, uma aquiescência maior dos parlamentares à agenda do executivo. Regras institucionais que estabelecem limites ao conteúdo e à forma das propostas dos parlamentares, bem como a organização centralizada do legislativo que confere poderes aos líderes partidários irão reforçar esta preponderância (MELO, 2005, p. 192). O fato de que os chefes de governos contam com recursos não-legislativos, oriundos do acesso que possuem aos postos de governo, Ihes garantirão ainda a sustentação política necessária para implementar seu programa de governo através da negociação de cargos na administração pública.

Se é verdade que este conjunto de prerrogativas institucionais oferece aos governos condições de governabilidade em contextos marcados pelo multipartidarismo, pela representação proporcional, pelo presidencialismo e pelo voto personalizado (SANTOS, 1997), é igualmente verdadeiro que esta governabilidade ocorre às custas do empobrecimento de um dos princípios fundamentais das democracias liberais representativas: o equilíbrio e o controle entre os poderes. No lugar da eqüipotência destes, tem-se uma hipertrofia do poder executivo (ABRÚCIO, 1998).

\footnotetext{
1 Agradeço os comentários críticos e as sugestões dos dois pareceristas anônimos da Revista Opinião Pública. Afirmo, porém, minha inteira responsabilidade pela versão final deste artigo.
} 
Assim, a democracia brasileira se vê diante de uma encruzilhada. Por um lado, sem os poderes conferidos por tais mecanismos institucionais tem-se a instabilidade política gerada pela configuração do presidencialismo aqui estabelecido, por outro, com a presença destes, tem-se o desequilíbrio de poderes e o comprometimento da própria democracia uma vez que esta requer, além de estabilidade política, a presença atuante de mecanismos de controle democrático que garantam a tradução da vontade dos cidadãos em decisões políticas legítimas².

Partindo dos próprios requisitos necessários a uma democracia representativa, este artigo pretende discutir a capacidade de novos arranjos institucionais ou não - em assegurar tanto o equilíbrio quanto o controle acima mencionados.

Baseando-se em uma experiência recente de governo no âmbito estadual - a gestão de Olívio Dutra (1999-2002) no Rio Grande do Sul - buscaremos analisar como a introdução de um conjunto de fóruns participativos implementados tanto pelo executivo estadual, através do Orçamento Participativo estadual, quanto pelo legislativo, através do Fórum Democrático, promoveu um padrão de relação diferente entre os dois poderes e destes com a sociedade neste estado ${ }^{3}$.

Para analisar os efeitos destes fóruns participativos sobre a prática democrática no Rio Grande do Sul, seguiremos o seguinte percurso: nas primeira seção, analisaremos a polêmica acerca da importância dos fóruns participativos na teoria democrática contemporânea; na segunda seção, mostraremos os conflitos gerados com a implantação do OP.RS; na terceira seção, as motivações para a introdução dos fóruns e a forma como eles contribuíram para restaurar o equilíbrio e o controle entre os dois poderes no RS serão analisadas. Por fim, na quarta seção, conclusiva, buscaremos mostrar como representação e participação podem tornarse mecanismos positivamente complementares para a efetivação de uma democracia que busca não só a governabilidade, mas a qualidade de suas práticas e instituições.

\footnotetext{
2 Argumento semelhante, apesar de algumas diferenças nos marcos teóricos, encontra-se em Anastasia e Melo (2004). Neste artigo, os autores buscam analisar "os efeitos combinados de diferentes instituições no que se refere à produção dos atributos considerados como desejáveis para a democracia: estabilidade e governabilidade, por um lado, accountability, responsiveness e densidade democrática da representação, por outro."

3 Sobre o padrão de relação entre as duas casas nos governos Collares (1990-1994) e Britto (1994. 1998), ver Abrúcio (1998) e Grohmann (2001). Segundo Abrúcio (1999), Collares, embora não possuísse maioria parlamentar, conseguiu garantir a aprovação da maioria de seus projetos através de negociação direta com os prefeitos e com os setores organizados da sociedade gaúcha que, por sua vez, pressionavam seus representantes parlamentares a aprovarem os projetos do executivo. Já o governo Britto construiu, com base na montagem de seu secretariado, uma coalizão partidária majoritária e coesa, composta por 36 dos 55 deputados, que garantia ao executivo a aprovação de seus projetos (GROHMANN, 2001).
} 
FARIA, C. F. Fóruns participativos, controle democrático e a qualidade da democracia...

A polêmica acerca da importância dos fóruns participativos na teoria democrática contemporânea

A centralidade dos fóruns públicos de discussão e deliberação na construção de decisões legítimas vem sendo enfatizada pela vertente deliberativa da democracia (HABERMAS, 1996; BOHMAN, 1996; DRYZEK, 2000). Acredita-se que o processo de decisão de um governo deve ocorrer mediante a participação e a deliberação de indivíduos racionais em fóruns amplos de debate e negociação. Essa deliberação não deve resultar de um processo agregativo das preferências fixas e individuais, mas sim de um processo de comunicação, em espaços públicos, que antecede e auxilia a própria formação da vontade (preferências) dos cidadãos.

Habermas (1996) é, com certeza, o pioneiro na tentativa de revalorizar, no contexto das sociedades complexas, a ampliação da participação política mediante a deliberação pública dos cidadãos nos fóruns públicos de participação. Este autor vem insistindo no fato de que as decisões políticas para serem legítimas necessitam estar ancoradas em um debate público que ocorre mediante a interação de pelo menos dois participantes, constituindo, assim, uma relação intersubjetiva calcada na força do melhor argumento. Para que esta argumentação se realize é necessária a presença de espaços públicos alternativos. Tais espaços, ao permitirem que os cidadãos e os seus representantes testem e justifiquem a validade de seus interesses e de suas razões antes de decidirem, passam a ser fundamentais juntamente com as eleições, a divisão de poderes e a regra da maioria - para garantir a legitimidade do processo decisório.

$\mathrm{O}$ argumento habermasiano de que a legitimidade de uma escolha política resulta da deliberação dos agentes livres, iguais e racionais nos espaços públicos, é questionado pelos críticos da democracia deliberativa (ELSTER, 1998; PRZEWORSKI et al., 1999; DAHL, 2000).

Na coletânea Deliberative Democracy, Elster afirma que a tomada de decisão coletiva por indivíduos livres, iguais e racionais não necessariamente precisa tomar a forma de deliberação. Existem outras formas de se alcançar tais decisões como a discussão, a barganha e o voto cujo uso depende do fator "tempo", crucial no processo de constituição de decisões vinculantes. Além do constrangimento temporal, esse autor considera a barganha e o voto, sem comunicação prévia, formas superiores de se alcançar decisões coletivas quando comparadas ao debate nos fóruns públicos. Para este autor , a publicização, tão enfatizada por Habermas no processo de deliberação, constitui, tão somente, uma "força cilizatória da hipocrisia", uma vez que induz e constrange os interlocutores a esconderem seus motivos básicos - a maximização de seus interesses privados - embora não os eliminem. Assim, a força civilizatória decorrente da publicização, ao mascarar os 
interesses privados como se fossem públicos, ofereceria um argumento second-best para a deliberação (ELSTER, 1998, p. 111).

Questões relativas aos sujeitos que deliberam, seus diferenciais de educação, informação e compromisso com o processo, aliadas às preocupações sobre os mecanismos institucionais da deliberação e sua capacidade de gerar acordos e decisões por meio de argumentos e não por meio do conformismo fazem parte do questionamento do autor sobre a validade da democracia deliberativa.

Assim como Elster, Stokes (1998), Przeworski (1998) e Jonhson (1998), elaboram, na mesma coletânea, uma série de críticas a essa forma de produzir decisões.

Stokes questiona o argumento segundo o qual a deliberação aumenta a qualidade das decisões e enriquece a democracia. Para a autora, a comunicação pública - deliberação - pode induzir as pessoas a assegurarem crenças causais ${ }^{4}$ que são inadequadas e que só promovem o interesse dos emissores das mensagens. Ademais, o potencial da deliberação de influenciar os cidadãos nos níveis mais profundos é questionado, uma vez que a identidade construída por meio da deliberação pode vir a ser politicamente debilitante para aqueles que a asseguram (STOKES, 1988, p. 124).

Para a autora, "se pseudo-preferências e pseudo-identidades são fenômenos comuns nas democracias, a deliberação terá também resultados normativamente desagradáveis" à medida em que ela abre espaço para que a política seja dirigida por interesses especiais que manipulam as noções dos cidadãos comuns sobre o que eles querem que o governo faça; na medida que ela pode substituir as preferências reais dos cidadãos comuns por preferências que os políticos imputam a eles e, por fim, à medida em que ela pode promover identidades que tais cidadãos provavelmente não assegurariam e que não são de seus interesses (STOKES, 1988, p. 135).

Assim como Stokes, o principal argumento de Przeworski (1998) é que a deliberação pode gerar "dominação ideológica", ou seja, os indivíduos irão assegurar crenças que não são tão boas para os seus interesses.

Embora concorde que a concepção agregativa de democracia é pouco atrativa e, às vezes, até mesmo incoerente, Przeworski acusa os proponentes da deliberação de não considerarem o fato de que a maioria das discussões públicas não está voltada para os objetivos e sim para os meios (melhor curso de ação para se alcançar objetivos). Segundo esse autor, se as preferências mudam no curso da deliberação, isso se deve ao fato de que as pessoas mudam suas crenças técnicas

\footnotetext{
${ }^{4}$ Derivadas das relações causais entre as políticas e os seus efeitos nas pessoas (STOKES, p. 124; PRZEWORSKI, p. 140).
} 
FARIA, C. F. Fóruns participativos, controle democrático e a qualidade da democracia...

ou o equilíbrio de crenças $^{5}$ sobre a eficácia política dos cursos alternativos da ação coletiva (PRZEWORSKI, 1988, p. 141). A deliberação sobre crenças técnicas deve envolver o reconhecimento da desigualdade de informação ou da habilidade de processá-la.

Por fim, Johnson elenca cinco desafios à deliberação enquanto mecanismo de tomada de decisão: 1) argumentos plausíveis sobre a deliberação não podem demandar tanto dos participantes. Para este autor, não é sensato antecipar que a deliberação transformará massivamente as preferências, a capacidade ou o caráter dos participantes de forma normativamente atrativa. (...) Seria mais razoável esperar que onde a discussão for bem sucedida, a deliberação promoverá a "boa fé" ao capacitar os participantes a desenvolverem uma compreensão maior um dos outros, uma confiança maior entre eles e no próprio processo de deliberação; 2) os argumentos sobre a deliberação não podem excluir os problemas derivados do auto-interesse e dos conflitos decorrentes da sua coordenação; 3) não está claro quais mecanismos possibilitariam as partes, no processo deliberativo, de convencerem ou persuadirem uns aos outros via argumentação; 4) uma explicação plausível da deliberação democrática deve, portanto, explicar quais formas institucionais o processo deliberativo deverá utilizar. Faz-se necessário, então, uma compreeensão melhor de como os arranjos deliberativos se relacionam com as instituições formais que envolvem a organização territorial da representação, bem como com o processo de votação; 5) um argumento plausível para a democracia deliberativa deve incluir ainda uma explicação sobre os efeitos que a deliberação pode gerar, bem como suas justificações. Não é suficiente insistir que os resultados que emergem da deliberação são o "acordo razoável". Para Johnson, argumentos plausíveis acerca da deliberação devem reconher que acordos substantivos sobre preferências e valores não são praticamente realistas ou normativamente plausíveis em cenários políticos pluralistas. Tais argumentos devem reconhecer que as demandas requeridas por tais acordos são muito altas quando se busca a deliberação como o remédio para os limites práticos (instabilidade) dos resultados gerados pelos mecanismos agregativos (JOHNSON, p. 176-177).

Se é fato que várias críticas arroladas sobre a validade dos mecanismos deliberativos devam ser consideradas, principlamente aquelas que enfatizam o diferencial de recursos entre aqueles que participam do processo deliberativo, temos, concomitantemente, aspectos importantes, ressaltados pelos próprios críticos, que tornam a presença dos fóruns deliberativos mais e não menos desejável.

\footnotetext{
${ }^{5}$ Modelo no qual os indivíduos estão presos a um equilíbrio ruim em função de suas expectativas sobre as crenças dos outros (PRZEWORSKI, p. 141).
} 
Como apontado por Przeworski e Johnson, na medida que as formas agregativas - os mecanismos eleitorais - não são suficientes para garantir a estabilidade das decisões e o controle sobre aqueles que a tomam, os fóruns podem servir não só como um canal que permite a racionalização do debate e da própria decisão por meio da discussão prévia, como aponta Elster, mas também como mais um espaço alternativo de mediação entre o eleitor e o representante cuja finalidade é assegurar uma ação mais responsável dos últimos. Desta forma, novos processos de ckecs and balances podem emergir com a introdução dos fóruns e de sua interação com os mecanismos formais de controle como o voto e a separação dos poderes.

Além disso, como a qualidade das decisões e a forma de implementá-las podem ser questionadas nestes espaços, eles acabam por proporcionar aos cidadãos comuns mais e não menos informação sobre suas escolhas, uma vez que os expõem às diversas dimensões de um mesmo tema em discussão (DRYZEK, 2000).

A "força civilizatória da publicização" e, conseqüentemente, dos fóruns onde ela ocorre, decorrerá, portanto, não só do constrangimento imposto às ações autointeressadas posto que ela traz consigo um componente simbólico que pode comprometer a reputação e o capital político daqueles representantes que não agem de acordo com o interesse comum (SMULOVITZ e PERUZZOTTI, 2000), mas, também, da explicitação de novos elementos contidos em uma determinada política e do controle exercido sobre a agenda política estabelecida.

Para aferir a validade dos diversos fóruns públicos implementados tanto pelo executivo quanto pelo legislativo estaduais no que diz respeito à sua capacidade de disseminar informações, controlar os representantes públicos e influenciar a produção de decisões coletivas, analisaremos, nas seções seguintes, a implantação do OP.RS e as conseqüências desta decisão para o o sistema político gaúcho.

A implantação do OP.RS e o conflito gerado entre os poderes executivo e legislativo no Rio Grande do Sul

O Orçamento Participativo estadual (OP-RS) foi implantado em 1999, primeiro ano do governo da Frente Popular.

Esta decisão, assim como outras iniciativas no campo da economia e da gestão pública assumidas pelo governo Dutra, estavam assentadas nas críticas imputadas à forma de condução neoliberal da economia e da política realizada nos âmbitos nacional e estadual desde meados da década de 90. 
FARIA, C. F. Fóruns participativos, controle democrático e a qualidade da democracia...

O governo Dutra buscou, assim, implementar ações e políticas de desenvolvimento que expandissem a economia, o emprego, a distribuição de renda e que potencializassem, de forma universal, os diversos setores da economia gaúcha.

Junto a esta intenção primeira, somou-se a visão de que a população gaúcha poderia auxiliar na integração deste tipo de desenvolvimento, uma vez que se acreditava que os fóruns do OP.RS gerariam uma lógica alocativa mais dispersa no território e mais diretamente beneficiadora das camadas de baixa renda. Desta forma, os investimentos das empresas e dos órgãos estatais deveriam ser guiados pela vontade expressa da população organizada nos fóruns do OP (SCHMIDT e HERRLEIN JR., 2004).

O caráter alternativo deste projeto de governo residia, portanto, não só no conteúdo do plano de desenvolvimento proposto, posto que visava recuperar o papel do estado e sua intervenção em áreas importantes como aquelas concernentes à oferta de serviços públicos e às políticas redistributivas, mas também na forma como ele foi implantado. Nele, as disposições societárias organizadas pelos fóruns do OP eram consideradas essenciais para guiar as ações dos órgãos governamentais que iriam implantá-las ${ }^{6}$.

Não obstante, em um contexto eleitoral marcado por uma eleição extremamente polarizada, onde a vitória de Olívio Dutra se deu por uma margem pequena de votos e por um contexto pós-eleitoral caracterizado pela formação de uma base parlamentar minoritária7, a implantação dos fóruns do OP causou uma série de conflitos. Esta iniciativa era avaliada pela oposição com o fim único de se obter apoio direto da população ao projeto de governo, ignorando as arenas usuais de mediação e processamento de conflitos, entre elas a própria Assembléia Legislativa do Rio Grande do Sul (ALRS).

São exatamente estes conflitos que buscaremos retratar nas próximas subseções juntamente com o padrão de solução construído pelas elites políticas gaúchas. Veremos que a introdução de mais fóruns de participação foi a resposta encontrada por elas. A análise das motivações que as levaram a optarem por este padrão de solução será realizada na terceira seção e, na seção conclusiva, buscaremos aferir qual foi o impacto desta escolha sobre a democracia no estado.

\footnotetext{
${ }^{6}$ Esta interpretação sobre a implantação do OP.RS difere daquela que vê o OP.RS como prioritariamente uma "construção de instituições para obtenção de vantagem partidária" e, assim, baseada em um cálculo instrumental do governo petista para conseguir apoio popular ao seu programa de governo (SCHNEIDER e GOLDFRANK, 2005).

${ }^{7}$ No primeiro momento 20 deputados e, depois, 12 dos 55 parlamentares.
} 
O coflito gerado com a implantação do OP-RS

Em janeiro de 1999, tanto o GRC quanto o GOF8 começaram a preparar a implantação do OP nos municípios do Rio Grande do Sul através de coordenadores regionais do OP, cuja função era mapear as principais lideranças locais sindicatos, associações de bairro, representantes das universidades, clubes de mãe, movimentos sociais, etc. - e convencê-las acerca da importância de implantar o OP no nínel estadual ${ }^{9}$.

A presença destes coordenadores nos diversos municípios-chave para a organização do OP desencadeou a primeira grande reação a este programa. Representantes dos Coredes ${ }^{10}$ viram com "indignação" a presença dos coordenadores nas suas áreas de atuação e tomaram a decisão de romper com o executivo estadual à medida em que se sentiram desprivilegiados pelo executivo estadual (JORNAL ZERO HORA, 13/03/99; p. 12). Com isto, criou-se um impasse entre os representantes do governo, dos Coredes e os deputados da oposição (PMDB, PPB, PTB, PSDB, PFL). Tal impasse tomou proporções jurídicas quando o deputado federal Alceu Collares (PDT) ingressou com uma ação popular contra o governo e em defesa dos Coredes ${ }^{11}$.

A justificativa do ex-governador era a mesma da dos presidentes dos Coredes: teria havido um desrespeito com um dos principais mecanismos de representação regional do estado à medida em que as funções dos coordenadores se sobrepunham às dos presidentes dos conselhos (JORNAL ZERO HORA, 31/03/99; p.12).

\footnotetext{
8 Gabinete de Relações Comunitárias e Gabinete de Orçamento e Finanças. Duas secretarias especiais criadas para coordenar as relações com a sociedade gaúcha e organizar as atividades previstas no OP.RS (GRC) e elaborar o Orçamento Público e o Plano de Investimentos e Serviços do OP.RS (GOF).

${ }^{9} \mathrm{Na}$ visão do governo, estas lideranças locais - vinculadas e/ou simpatizantes do PT e de seus aliados serviriam como multiplicadores da idéia, dado que a implantação do OP estadual envolvia um problema de escala - espacial, temporal e jurídica - que não estava colocado para esta mesma iniciativa no nível estadual. Para a análise das variáveis que atestam a maior complexidade envolvida na estadualização do OP.RS, ver Faria (2006).

10 Conselhos de Desenvolvimento Regionais, criados pela Lei 10.283/1994 de iniciativa das lideranças regionais. Sua função é auxiliar o governo no planejamento das diversas regiões que compõem o estado. Sua composição envolve deputados estaduais e federais com domicílio eleitoral na área de abrangência do conselho, prefeitos e presidentes das câmaras de vereadores, Representantes das instituições de ensino superior que atuam na região e representantes das associações, sindicatos e conselhos setoriais criados por lei (COREDES-RS, 1999).

11 Collares foi responsável pela implantação dos Coredes no estado quando foi governador no período 1989-1993.
} 
FARIA, C. F. Fóruns participativos, controle democrático e a qualidade da democracia...

A solução para este conflito ocorreu mediante um acordo firmado entre o executivo estadual e os representantes dos Coredes no qual foram previstas mudanças na organização e na metodologia do OP, bem como na representação do COP.

Os Coredes, juntamente com os coordenadores, passaram a ser responsáveis pela organização e coordenação das assembléias do OP-RS.

Metodologicamente, a dinâmica do OP mudou ${ }^{12}$. A primeira fase do OP. 2000 começou com as Plenárias Regionais de Diretrizes e não mais com as Assembléias Municipais como em 1999. A lista de prioridades regionais passou a ser definida nestas plenárias e passou a servir de parâmetro para organizar a Lista Tipo $^{13}$. Com isso, o executivo acatou a reivindicação dos Coredes de manter a definição das prioridades do OP em bases regionais. Ademais, os representantes dos Coredes passaram a participar do processo de deliberação sobre os programas de desenvolvimento regional sem serem submetidos ao processo de votação através do qual os delegados eram eleitos. Foi criado, para isto, um sistema misto de decisão por meio do qual os representantes dos Coredes foram integrados ao COP com direito a voto.

\footnotetext{
${ }^{12}$ A dinâmica do OP.RS era composta de três fases distintas compostas por um conjunto de plenárias e assembléias públicas cujas finalidades eram debater e decidir com a população gaúcha a alocação dos recursos orçamentários do estado. Seu ciclo envolvia todo o ano, começando em janeiro, com as plenárias preparatórias e terminando em setembro, com a posse do Conselho do Orçamento Participativo. A $1^{\text {a }}$ fase era composta pelas Plenárias Regionais de Diretrizes (PRDs), pelas Assembléias Temáticas de Desenvolvimento (ATDs) e pelas Assembléias Públicas Municipais (APMs). A $2^{\text {a }}$ fase envolvia duas Plenárias Regionais de Delegados (PRDs) onde os delegados eleitos buscavam compatibilizar as demandas votadas e elegiam o Conselho do OP.RS (COP.RS) e a Comissão Representativa (CR). Na 3a. fase, o Conselho do Orçamento Participativo era empossado. Iniciava-se, então, a fase de elaboração da Matriz Orçamentária e do Plano de Investimento e Serviços que envolvia as secretarias e os órgãos do estado e as instâncias representativas do OP. De posse da proposta orçamentária, O COP e a CR discutiam-na com os delegados do OP nas 23 regiões do estado. O retorno deste debate era apresentado ao governo e, após os ajustes necessários, o COP.RS deliberava a proposta orçamentária final e a entregava para o governador do estado. Até o dia 15 de setembro, o governador entregava a proposta à assembléia legislativa do Rio Grande do Sul (ALRS) cuja atribuição é apreciar, emendar e votar o Projeto de Lei do Orçamento do estado entre os dias 15/09 a 30/11 de cada ano.

13 A Lista Tipo é um caderno distribuído aos participantes do OP.RS onde estão discriminados os programas, as obras e os serviços que eram escolhidos pelos mesmos. Seu objetivo era "orientar a população sobre os procedimentos para propor, debater e votar suas prioridades nos programas estaduais de desenvolvimento e em serviços e obras de competência estadual para o orçamento do estado" (Governo do Estado. OP.RS: Orientações para Propostas, Debates e Votações nas Assembléias 2001).
} 
Um outro ponto de conflito entre executivo, Coredes e legislativo foi o cumprimento das prioridades definidas na Consulta Popular ${ }^{14}$. Como o executivo ignorou, no primeiro momento, as consultas realizadas em 1998, tanto os representantes dos Coredes quanto os deputados de oposição (35 dos 55 deputados) ameaçaram entrar na justiça. 0 governo reagiu mediante ação direta de inconstitucionalidade no Supremo Tribunal Federal demandando a suspensão da Lei da Consulta. Para a oposição, a tentativa de suspensão das Consultas constituía uma prova cabal da utilização do OP como um "instrumento de propaganda das administrações petistas" (JORNAL ZERO HORA, 20/05/99; p. 6).

Além dos impasses supracitados, o governo foi judicialmente proibido de usar veículos, pagar despesas e utilizar funcionários na dinâmica do OP.RS.

Mesmo assim, o OP.RS persistiu, contando, para isto, com toda a rede associativa convocada a participar de sua implantação e com os delegados eleitos na primeira fase.

Acrescenta-se a este quadro de disputa, um outro ponto de conflito: os deputados de oposição passaram a exigir a regulamentação do OP-RS por lei.

Esta é uma antiga reivindicação da oposição no âmbito municipal que passou a ser defendida pelos deputados estaduais mediante a justificativa de que legalizado, O "OP seria controlado por uma série de instituições como os poderes legislativo e judiciário e não seria mais utilizado como marketing eleitoreiro e partidário" (Informativo do Deputado Paulo Odone - PMDB/maio-2000).

Diante da recusa do executivo, esses mesmos deputados resolveram criar uma versão do OP.RS no legislativo. A oposição passou a elaborar uma proposta de discussão popular dos orçamentos anuais com o objetivo explícito de se contrapor ao OP estadual (JORNAL ZERO HORA, 21/06/99; p. 14).

\footnotetext{
${ }^{14}$ Consulta Popular: mecanismo de participação na definição das obras de investimento do estado criado no último ano do governo Antônio Britto (PMDB) pela Lei 11.179 - Decreto no. 38.610 de 25/06/1998. A Lei previa que pelo menos $35 \%$ dos recursos livres destinados para o investimento fossem rateados entre as 22 regiões dos Coredes, cabendo aos Coredes elaborar uma lista de 10 a 20 obras consideradas prioritárias que era submetida à votação popular através de urnas distribuídas nos municípios. As cinco prioridades mais votadas em cada região deveriam constar no Orçamento para o próximo ano (Governo do Estado do RS. Secretaria da Coordenação e Planejamento. Ago/1998).
} 
FARIA, C. F. Fóruns participativos, controle democrático e a qualidade da democracia...

A reação da $A L R S$ aos fóruns participativos do OP-RS

Como reação ao "jeito petista de governar", os deputados da oposição criaram o Fórum Democrático de Desenvolvimento Regional ${ }^{15}$, ampliando ainda mais os espaços públicos de debate sobre o projeto orçamentário.

O objetivo do Fórum era viabilizar a participação dos cidadãos nas discussões da assembléia legislativa sobre questões prioritárias para o desenvolvimento do RS. Em vez de utilizar de suas prerrogativas constitucionais e emendar o projeto orçamentário nos gabinetes e nas comissões parlamentares, a oposição propôs fazer um debate externo em todas as regiões do estado.

Assim como a implantação do OP estadual, a criação do Fórum Democrático causou uma série de conflitos entre governo e oposição: embora apoiado integralmente pelos deputados de oposição, os deputados governistas consideraram o fórum um terceiro turno das eleições de 1998 e resistiram à sua implantação. Entretanto, acordo firmado entre ALRS, Coredes, União dos Vereadores do Rio Grande do Sul (Uvergs) e Federação dos Municípios do Rio Grande do Sul (Famurs) assegurou a confecção e a aprovação da resolução $n^{\circ} 2771$ de 8/9/199 que criou o fórum na ALRS.

A partir de setembro de 1999, o estado do Rio Grande do Sul passou a ter dois processos participativos na confecção orçamentária: o OP.RS, uma iniciativa do executivo estadual e o Fórum Democrático, uma iniciativa dos deputados da oposição na ALRS. Criou-se, portanto, uma "onda participativa" em torno da definição do orçamento do estado que, como mostra o gráfico abaixo, se estendia de março a novembro de cada ano.

15 Objetivos do Fórum Democrático eram (1) debater com os cidadãos os assuntos de interesse da sociedade; (2) construir políticas regionais de desenvolvimento; (3) propor investimentos de interesse regional; (3) fiscalizar a aplicação de recursos públicos; (4) assegurar a participação da sociedade gaúcha no processo de discussão do Projeto de Lei Orçamentária, fiscalizar e controlar a sua execução. Participam os cidadãos, os representantes dos segmentos organizados, os vereadores, os prefeitos e os deputados estaduais. A dinâmica do fórum ocorre mediante 4 etapas: $1^{\text {a }}$ ) a ALRS recebe o projeto do executivo e o entrega detalhado para os COREDES que ficam responsáveis pela análise das possíveis alterações; $2^{\mathrm{a}}$ ) Os COREDES encaminham as propostas aos Conselhos Municipais de Desenvolvimento; $\left.3^{a}\right)$ Os COMUDES convocam assembléias populares em cada município para debater o projeto final; $4^{a}$ ) as prioridades definidas nas assembléias municipais são encaminhadas à comissão de finanças e planejamento da ALRS. Essa comissão promove audiências públicas nas então 22 regiões do estado com o objetivo de ouvir as necessidades locais. Depois das audiências, esta comissão analisa a viabilidade técnica, financeira e jurídica das propostas recebidas. O texto final deve ser votado pela ALRS e sancionado pelo governador até o dia 30 de novembro. (Assembléia Legislativa do Rio Grande do Sul. Fórum Democrático. 1999). 


\section{Gráfico 1}

\section{Ciclo de debates e votação do Orçamento Estadual no RS}

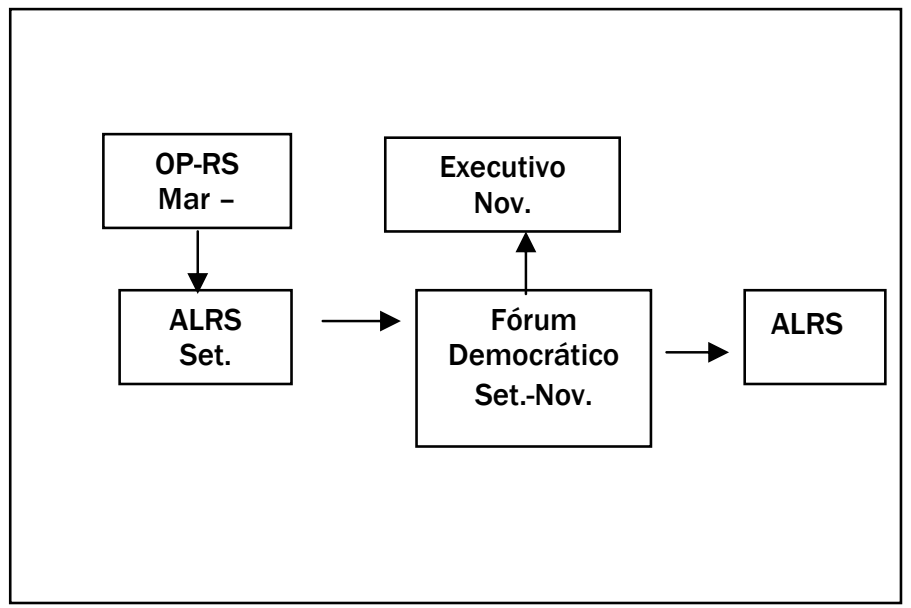

Depois das assembléias do OP, o texto orçamentário passou a contar com mais uma bateria de discussões em audiências públicas coordenadas pela Comissão de Finanças e Planejamento da assembléia legislativa. Essa comissão, presidida por um deputado ligado ao partido do governo, saía em caravana pelas então 22 regiões do estado. As audiências públicas organizadas pelo legislativo estadual eram abertas à população e tinham como finalidade debater e sistematizar as emendas que seriam agregadas ao texto original do orçamento ${ }^{16}$.

Embora com resistência, o executivo cedeu tanto em relação à realização das obras votadas na consulta popular, que passaram a constar no projeto orçamentário do governo, quanto em relação ao fórum. O secretário do GOF passou a participar de todas as audiências públicas do fórum, prestando esclarecimentos e debatendo o projeto orçamentário elaborado.

Depois de finalizadas as audiências públicas do Fórum Democrático, o novo embate entre o executivo e o legislativo ocorreu em torno do número de emendas ao projeto. Sob forte crítica dos parlamentares de oposição ao projeto orçamentário enviado à ALRS que, segundo eles, não estava contemplando as promessas de

\footnotetext{
16 Tais emendas precisavam ser assinadas por duas entidades representativas ou por pelo menos 500 pessoas, precisavam conter a fonte de recursos e deviam estar de acordo com o Plano Plurianual de Investimentos e com a Lei de Diretrizes Orçamentárias. Se aprovadas, eram votadas em plenário pelos 55 deputados. 0 texto final era entregue ao governador até o dia 30/11 de cada ano para ser sancionado até o dia 15/12. O governador podia vetar as emendas, assim como a ALRS podia derrubar o veto do governador.
} 
FARIA, C. F. Fóruns participativos, controle democrático e a qualidade da democracia...

campanha, o executivo começou a negociar o número de emendas ao projeto orçamentário proposto através do fórum democrático. Temendo sua desfiguração, o governo argumentou com base na tradição do legislativo de não acatar um número excessivo de emendas (cf. quadro abaixo). Em função das negociações entre os dois poderes, as prioridades do projeto original do governo foram mantidas em sua essência: das 1276 emendas apresentadas pelos deputados (415), pela população (177) e pelas comissões (648) apenas 224 foram aprovadas no plenário. Destas, o executivo vetou 92 .

Quadro 1

Número de emendas apresentadas e aprovadas pela Comissão

\begin{tabular}{|l|c|c|c|c|c|}
\hline Ano & 1995 & 1996 & 1997 & 1998 & 1999 \\
\hline No. de Emendas & 471 & 675 & 552 & 1758 & 251 \\
Aprovadas & 58 & 33 & 28 & 23 & 29 \\
\hline
\end{tabular}

Fonte: JORNAL ZERO HORA

A aprovação do projeto foi comemorada tanto pelo governo quanto pela oposição. Governistas sentiram-se aliviados, à medida em que conseguiram preservar as prioridades do OP estadual e evitar mudanças maiores no projeto orçamentário. A oposição ficou satisfeita por ter conseguido aprovar suas emendas através do fórum democrático, obrigando o governo a reconhecê-lo. Por fim, depois de oito meses de discussão em todo o estado, o orçamento estadual para 2000 foi aprovado.

As polêmicas em torno do projeto do executivo no que diz respeito à confecção do orçamento do estado redefiniram a agenda do legislativo. Em 2000, o legislativo decidiu aproximar-se ainda mais da sociedade. Tal orientação consta no depoimento do novo presidente da casa, deputado Otomar Vivian (PPB): "a essência da $A L$ é a democracia representativa, mas todos nós estamos vendo um avanço da democracia participativa" (JORNAL ZERO HORA, 31/01/2000; p. 6). O pepebista tinha como meta para o seu mandato reforçar essa linha de atuação que, no ano anterior, culminou com o surgimento do fórum democrático.

Tal declaração reafirma o "consenso" que se formou em torno do modelo participativo introduzido pelo executivo para elaborar o orçamento do estado. Uma vez que não podiam se opor às assembléias do OP sem se desgastarem politicamente, a estratégia da oposição foi criar novos fóruns participativos que dessem legitimidade às emendas e/ou vetos que seriam apresentados. 
Assim como Otomar Vivian, o ex-presidente da casa, deputado Paulo Odone (PMDB), também ressaltou a importância da dinâmica participativa que agora era executada pelos dois poderes. Segundo Odone, um dos pontos positivos de sua gestão foi a criação do fórum democrático e o surgimento de um "novo clima" nas relações entre os dois poderes. Para o deputado, o diálogo entre eles avançou e as dificuldades anteriores foram superadas ${ }^{17}$.

Em que pese o diagnóstico apresentado, os dois anos subseqüentes do governo Olívio Dutra foram também marcados por uma série de conflitos entre as duas casas resolvidos, por vezes, por decisão judicial. Além da presença do judiciário, tanto o executivo como o legislativo contaram também com os seus respectivos fóruns participativos cujo objetivo era debater e publicizar as suas propostas, construindo formas alternativas de legitimidade para os projetos em disputa. Duas situações ilustram bem como esses fóruns participativos reconformaram os impasses criados entre os dois poderes: 1) a discussão sobre a mudança da matriz tributária estadual proposta pelo governo e 2) o debate sobre a criação da Universidade Estadual do Rio Grande do Sul (UERGS) ${ }^{18}$.

Em meio à comemoração resultante da decisão do Supremo Tribunal da Justiça (STJ) de liberar os gastos públicos na execução do OP.RS, o executivo deparou, no segundo ano, com a resistência da ALRS em alterar as alíquotas do ICMS cuja finalidade era, segundo o governo, promover a justiça fiscal. No ano seguinte, um novo impasse foi criado frente à proposta do executivo de implementar uma das principais demandas do OP.RS e promessa de campanha do governador Olívio Dutra: a universidade estadual.

Tanto as plenárias do OP.RS quanto às do fórum democrático passaram a deliberar sobre estes dois temas contensiosos.

Nas assembléias do OP-RS, o executivo apresentava e debatia com os participantes suas propostas e explicitavam as divergências em torno dos projetos de governo, politizando, assim, o debate. Uma vez convencidos da validade destas propostas, os delegados e os conselheiros do OP pressionavam os seus representantes no legislativo que, por sua vez, tinham de explicar porque não acatariam essa ou aquela proposta gestada no âmbito governamental.

Nas audiências públicas promovidas pelo fórum democrático, o legislativo seguia o mesmo padrão de ação: debatia com a população gaúcha a qualidade das propostas e justificava publicamente o possível veto ao executivo. Propunha ainda meios para qualificar as propostas antes de serem votadas no plenário da ALRS.

No caso da mudança na matriz tributária, que já tinha sido vetada pelo legislativo no ano anterior, o governo resolveu introduzir o tema nas assembléias do

\footnotetext{
17 Entrevista realizada em Junho de 2000.

18 Descrição mais detalhada destas iniciativas e dos impasses decorrentes encontra-se em Faria (2002).
} 
FARIA, C. F. Fóruns participativos, controle democrático e a qualidade da democracia...

OP-RS/2000, argumentando que as mudanças por ela impulsionadas eram essenciais para o cumprimento das despesas do orçamento. Embora contando com o apoio do COP-RS e de parte dos prefeitos que seriam beneficiados com o aumento seletivo do ICMS, a matriz tributária não foi implementada. A maioria dos deputados, que considerava uma "chantagem" do governo vincular o aumento das alíquotas do ICMS ao cumprimento do projeto orçamentário, vetou o projeto. Entretanto, antes de fazê-lo, eles realizaram, no interior do estado, uma série de debates sobre o tema, reunindo no fórum representantes de diferentes entidades: empresariais e trabalhistas, associações comunitárias, representantes do OP, do governo e da mídia.

No caso da criação da UERGS, o padrão de conflito foi o mesmo, embora a solução tenha sido diferente. O projeto de Lei 01/2001, que versava sobre a criação da UERGS, sofreu inúmeras críticas quando chegou na ALRS. Diante da reação dos parlamentares, a mesa diretora da ALRS decidiu que o fórum democrático concentraria seus esforços no projeto de criação da UERGS. Pela primeira vez, o fórum discutiu um tema desvinculado da área orçamentária.

Além de ter sido debatido nas assembléias do OP, a população gaúcha pôde discutir e apresentar emendas ao projeto de Lei 01/2001 nas então 22 audiências públicas organizadas pela comissão de educação, cultura, desporto, ciência e tecnologia da ALRS.

A caravana do fórum democrático começou em abril e prosseguiu até o final de maio contando com uma participação expressiva da população gaúcha ${ }^{19}$. Temas como custo e financiamento da nova instituição levaram representantes de diversas categorias do ensino médio e universitário a polemizarem com o executivo. Após um ciclo de 22 audiências públicas no interior do estado, esta comissão sistematizou e protocolou as emendas e as propostas recebidas durante o fórum. 0 governo acatou tais sugestões, modificando a proposta inicial das discussões ocorridas nas audiências públicas seguintes.

O saldo resultante do embate em torno do projeto da UERGS ilustra bem o papel positivo desempenhado pelos fóruns na produção de decisões vinculantes: de um cenário marcado pelo impasse entre o governo e a oposição acerca do projeto de lei de criação da UERGS, chegou-se à aprovação unânime dos 40 deputados que participaram da sessão. Para a oposição, que temia que o projeto da UERGS se constituísse em mais um trunfo eleitoral para o governo, o debate realizado thes permitiu apropriar de um projeto gestado pelo executivo e eleitoralmente importante, uma vez que explicitaram publicamente as fragilidades contidas na sua

\footnotetext{
${ }^{19}$ Ao acompanhar a reunião do fórum democrático sobre a implantação da UERGS em Novo Hamburgo (10/05/2001), constatei a presença de mais de 600 pessoas. Os dados sobre a participação total nos 22 fóruns não foram computados pela secretaria do fórum democrático, mas o padrão participativo das audiências foi, segundo o secretário executivo do mesmo, igual ou superior ao de Novo Hamburgo.
} 
primeira versão. Para o governo, gestor de uma demanda histórica de setores da população gaúcha, as sugestões oriundas das audiências públicas serviram para aprimorá-lo. E, finalmente, mas não menos importante, a população envolvida viu sua demanda aprovada em condições melhores posto que exaustivamente debatida.

Os padrões de conflito entre os dois poderes, no nível estadual, como decorrência da implantação do OP-RS diferenciaram daquilo que comumente ocorre no nível municipal.

$\mathrm{Na}$ câmara dos vereadores, a reação mais comum era, no primeiro momento, de repúdio à implantação do OP. Posteriormente, os vereadores começaram a disputar com as lideranças locais e com a administração municipal a alocação dos recursos do orçamento e a paternidade das obras executadas (FARIA, 1996; FEDOZZI, 1999; DIAS, 2002). Paralelamente, buscavam institucionalizar o OP, reivindicação também feita pelos deputados estaduais.

Diante da resistência dos gestores - municipais e estaduais - à demanda de institucionalização, a atitude dos deputados de oposição frente à implantação do OP-RS foi bem diferente, uma vez que a introdução dos fóruns participativos passou a fazer parte tanto da realidade do executivo petista, que já os utilizavam no âmbito municipal, como do legislativo, que não possuía esta tradição. Esta diferença ganha maior relevância se levarmos em conta as estratégias usualmente utilizadas pelos governadores para impor e implementar suas políticas, sem grande resistência dos legisladores (ABRÚCIO, 1998; FIGUEIREDO e LIMONGI, 1999; SANTOS, 2001; MELO, 2005) $)^{20}$.

Vale a pena, portanto, analisar as motivações que levaram os dois poderes a implementar tais fóruns participativos.

\footnotetext{
20 É conhecida a tese de Abrúcio (1998) sobre o ultrapresidencialismo estadual. Segundo o autor, o sistema político estadual brasileiro é definido basicamente pelo governador que possui instrumentos políticos suficientes para cooptar a classe política formando coalizões que tornam o executivo estadual um poder sem controle institucional. No que diz respeito especificamente ao orçamento estadual, o autor afirma que, de um modo geral, as assembléias legislativas brasileiras tiveram um papel meramente homologatório no período analisado (1991-94) baseado no que ele chama de "pacto homologatório" que ocorre entre executivo e legislativo estaduais. Dois elementos sustentam tal pacto: a cooptação dos deputados através da distribuição dos recursos clientelistas e a ausência de participação e responsabilização dos parlamentares diante das políticas públicas implementadas pelo executivo ( $p$. 113-115). Na coletânea organizada por Santos (2001), sobre a relação entre os legislativos e os executivos estaduais, Grohmann (2001), que analisou o caso do Rio Grande do Sul entre os anos 1995. 1998, constatou o mesmo padrão de relação entre os poderes.
} 
FARIA, C. F. Fóruns participativos, controle democrático e a qualidade da democracia...

As motivações para a introdução dos fóruns e a restauração do equilíbrio entre os dois poderes no RS

Pelo menos três variáveis explicam a formação de novos fóruns públicos no RS resultante das inciativas não só das lideranças do executivo, mas também das lideranças do legislativo estadual: (1) a tradição associativa existente no RS; (2) o sucesso do OP municipal em Porto Alegre e (3) a percepção de certos deputados de que a criação de mais um canal participativo nos moldes petistas daria maior legitimidade às suas ações dado que eles lhes permitiriam debater, publicizar, questionar e controlar publicamente a qualidade dos atos do executivo, bem como suas possíveis omissões.

Diante do conflito de poder estabelecido entre as duas casas, a solução encontrada foi a implantação de mais canais participativos, uma linguagem que se tornou comum à população gaúcha.

\section{A tradição associativa do $R S$}

Embora apresentando diferenças regionais importantes no que diz respeito às suas tradições associativas, o RS possui uma densidade associativa cuja origem encontra-se nos movimentos populares e sociais que emergiram nos períodos anteriores e deram sustentação ao processo de redemocratização no país (BAIERLE, 1992; SILVA, 2001), no sistema partidário plural e competitivo, composto por partidos bem estruturados regionalmente como é o caso do PT, PPB, PMDB, PTB, PDT, além dos partidos com menor representação como o PFL, PSDB, PC do B e o PPS, em uma série de entidades representativas como a dos trabalhadores rurais (Federação dos Trabalhadores Agrícolas, Movimento dos Pequenos Agricultores, Movimento dos Trabalhadores Rurais Sem Terra), como a do movimento sindical (CUT e CGT), a dos municípios (FAMURS), a dos empresários (FEDERASUL), a dos vereadores (UVERGS), além dos inúmeros conselhos como os Coredes, os Comudes, os Conselhos Gestores de Educação, Saúde, Direitos Humanos, Assistência Social, etc.

Essa rede composta por diferentes atores foi extremamente importante na operacionalização tanto do OP-RS, como do fórum democrático. Parte dela sustentou, por exemplo, a organização do OP estadual no período em que o governo foi impedido judicialmente de alocar recursos estaduais na sua organização. Como declarou o presidente da CUT/RS, "a CUT, seus sindicatos, os partidos políticos que sustenta[ram] o governo e outras entidades garanti[ram] o apoio, os recursos e 
os encaminhamentos necessários para que este processo de democracia e transparência funcion[asse]" (MARQUES, 1999, p. 185).

Os delegados do OP também pertenciam a esta rede, pois apresentavam múltiplas filiações representativas com as associações de moradores, com os grupos religiosos e/ou culturais, com os conselhos setoriais e populares, com as ONGs, com os sindicatos e com os partidos políticos.

Por outro lado, a constituição do fórum democrático também contava com o apoio de diversos grupos organizados. Os Coredes, os Comudes, as entidades representativas dos municípios, dos vereadores, dos empresários, dos conselhos setoriais e de setores da universidade deram sustentação política à decisão dos deputados da oposição de criarem o fórum. Ademais, pode-se afirmar que aqueles que freqüentaram as audiências públicas realizadas pelo fórum também possuíam, tal como os delegados do OP.RS, diferentes vínculos associativos e políticos uma vez que o direito de voto nas audiências pressupunha, institucionalmente, alguma vinculação com as entidades representativas. Somente os representantes das entidades tinham direito de voto nestas reuniões ${ }^{21}$.

O que temos neste estado, portanto, é um conjunto de atores com uma vivência associativa que conformou um ambiente propício para a criação não só do OP.RS, mas também do fórum democrático.

O sucesso do OP-PoA

O êxito que estamos atribuindo ao OP.PoA baseia-se em uma série de análises sobre o tema em questão. Depois de mais de 12 anos de sua implantação, esse mecanismo teria contribuído tanto para a democratização das relações entre o poder público municipal e a sociedade civil quanto para uma distribuição mais eqüitativa dos bens públicos municipais gerando aquilo que Santos (1998) denominou de "justiça distributiva".

Como ressaltou Avritzer (2002), um dos elementos que confirma tal democratização é a própria dinâmica do OP. As assembléias municipais (os fóruns), ao criarem um método público de decisões das obras, acabam por fornecer uma outra resposta ao particularismo e a forma opaca de tomada de decisão usual nas administrações brasileiras. Além disso, a formação de instâncias como o conselho do OP permitem aos representantes monitorarem as ações da prefeitura, rompendo

\footnotetext{
${ }^{21}$ Cortês mostra a diferença entre as vinculações políticas dos participantes do OP.RS e dos integrantes dos Coredes, um dos principais integrantes do fórum democrático. Segundo a autora, enquanto no OP destacavam-se pessoas vinculadas à FETAG, ao MPA, ao MST, à CUT e à comunidade escolar das escolas estaduais públicas, os integrantes dos Coredes eram vinculados à ALRS, às prefeituras, às câmaras de vereadores, aos sindicatos patronais, etc. (CORTÊS, 2004, p. 10-11).
} 
FARIA, C. F. Fóruns participativos, controle democrático e a qualidade da democracia...

também com a prática de insulamento das burocracias locais. Ademais, ao transferir para a população a decisão sobre a distribuição dos bens públicos, por meio das assembléias públicas e de critérios publicamente discutidos, o OP.PoA obstaculariza a ação dos mediadores políticos (vereadores, agentes da administração municipal, etc.) criando uma relação mais eqüânime na distribuição destes bens (p. 14-15).

O efeito do OP pode ser sentido também na própria burocracia municipal. Navarro (1998) mostrou, por exemplo, como a implantação deste mecanismo afetou a capacidade da administração municipal de construir, na cidade, a rede de saneamento público. O desempenho dos órgãos responsáveis aumentou quantitativa e qualitativamente depois do OP municipal. Ora, maior eficiência da máquina em implementar tais bens acaba por gerar maior eqüidade no atendimento das demandas resultantes deste processo participativo ${ }^{22}$.

Tais fatos atestam o êxito que este mecanismo participativo alcançou no nível municipal, comprovado também pela aprovação eleitoral dos governos petistas durante mais de uma década. Obviamente, este sucesso eleitoral serviu aos dirigentes petistas como inspiração para a decisão de estadualizar o OP. Residia aí o temor da oposição. Com o OP municipal, a administração petista vinha permanecendo no poder por vários anos, representando para a oposição uma ameaça.

\section{O cálculo dos deputados}

O contexto político que levou a criação do Fórum Democrático esteve intimamente relacionado à implantação do OP-RS. Aqueles que o implantaram consideravam o OP.RS um mecanismo de legitimação da proposta de governo. Ao debatê-la nas assembléias públicas, o governo ganhava respaldo popular e, ao mesmo tempo, dificultava a ação dos parlamentares tanto no que diz respeito às emendas, quanto aos possíveis vetos ${ }^{23}$.

Mediante tal avaliação, a oposição buscou politizar o debate em torno do orçamento estadual através das audiências públicas do fórum democrático.

O recurso ao arranjo participativo criado pela ALRS permitiu aos deputados disputarem com o executivo a legitimidade do projeto orçamentário e continuarem a exercer o seu papel de "agenciador", dado que garantiam as verbas necessárias às suas clientelas por meio de emendas na votação da comissão. Tais emendas

\footnotetext{
22 Sobre o caráter redistributivo do OP.PoA ver Marqueti (2003).

23 Tal afirmação apareceu nas entrevistas realizadas com os dois presidentes da casa (mandatos 1999 e 2001).
} 
passaram a ter também respaldo popular como os programas temáticos, as obras e os serviços do OP.RS.

Mas este não teria sido o único efeito do fórum: segundo o presidente da comissão de finanças e planejamento da ALRS (1999-2001), tal arranjo teria proporcionado (1) uma racionalização do número de emendas propostas, sejam elas de origem popular, dos deputados ou das comissões parlamentares; (2) uma ampliação do debate sobre o orçamento, à medida em que setores que não participaram do OP.RS encontraram nas audiências do fórum um espaço para debater e demandar propostas que não foram contempladas pelo OP-RS e, por fim, (3) mais uma oportunidade para o executivo reafirmar o seu projeto orçamentário uma vez que o secretário do GOF era convidado a apresentar e debater com a população e os deputados presentes o projeto original e as possíveis emendas apresentadas $^{24}$.

Os debates ensejados pela criação da UERGS ilustram o círculo virtuoso que este desenho participativo causou na relação entre executivo e legislativo estaduais. Segundo o presidente da ALRS (2001), Sérgio Zambiase (PTB), "se o projeto de autoria do executivo não fosse publicamente debatido nas audiências do Fórum, as emendas que, com certeza, os deputados fariam ao projeto inicial seriam alvo de críticas do executivo, de polêmica com a população e indutora de mais um desgaste desnecessário. Uma vez debatido com os diversos setores representativos, os deputados sentiram-se mais confiantes em relação às prováveis emendas". As discussões prévias informaram, portanto, o voto dos parlamentares e, por outro lado, informaram também a decisão do executivo de aperfeiçoar o projeto.

Mas a virtude do debate estabelecido não está unicamente na capacidade dos parlamentares de emendar ou não os projetos do executivo com respaldo popular, mas no fato de esta casa voltar a exercer uma de suas importantes funções, qual seja, a de contrapeso ao poder executivo, reequilibrando, assim, a relação entre os dois poderes.

Aqui vale a pena voltar às teses sobre a predominância do executivo sobre o legislativo. Tomando Abrúcio como ponto de partida, é possível ver como os governadores conseguem manter o seu domínio sobre o processo decisório ao buscarem neutralizar a possibilidade dos outros poderes de controlarem institucionalmente o executivo destruindo, assim, o princípio de checks and balances (ABRÚClO, 1998, p. 111).

No Rio Grande do Sul, com a introdução do OP.RS e do fórum democrático, foram reforçados tanto os mecanismos verticais de controle do executivo, quanto os mecanismos horizontais. À medida em que publicizavam o debate, os deputados acabaram por ajudar a população gaúcha a aperfeiçoar projetos relevantes e a

\footnotetext{
${ }^{24}$ Entrevista realizada com o presidente da comissão de finanças e planejamento da ALRS em 07/2000.
} 
FARIA, C. F. Fóruns participativos, controle democrático e a qualidade da democracia...

fiscalizar as suas capacidades de execução pelo executivo. Juntamente com a comissão representativa e o conselho do OP.RS, os deputados controlavam o executivo, exigindo deste que cumprisse aquilo que foi deliberado nas assembléias do OP, transformando a peça orçamentária de ficção em algo real. Por isso, a emenda constitucional de autoria dos deputados da oposição que obrigava o governo a cumprir aquilo que estava na lei orçamentária passou a ter um duplo sentido: por um lado, era mais uma forma de se opor ao governo e uma tentativa de desgastar o seu principal instrumento de gestão pública, mas, por outro lado, eles exerciam o papel de fiscalizadores da capacidade de execução da lei orçamentária, reforçando, assim, o "espírito" do OP.RS.

\section{Notas conclusivas}

Partindo do pressuposto que tanto variáveis internas ao processo legislativo quanto externas podem colaborar no sentido de restaurar os pressupostos básicos de uma democracia representativa ${ }^{25}$, principalmente àqueles concernentes ao equilíbrio entre os poderes e ao controle exercido sobre eles, este artigo teve como objetivo discutir a efetividade dos fóruns deliberativos no aperfeiçoamento da prática democrática no Rio Grande do Sul.

Como foi relatado, a implantação dos fóruns participativos no estado decorreu da decisão do governo estadual de expandir o OP para o estado. O contexto no qual esta decisão foi tomada era caracterizado por uma polarização ideológica acirrada que se traduziu, através do processo eleitoral, em número de cadeiras na assembléia legislativa deste estado. O ex-governador ganhou a eleição, mas não conseguiu maioria na câmara, ao contrário, sua base aliada era minoritária.

A introdução das assembléias públicas do OP-RS possibilitou ao governo ampliar sua base de apoio à medida em que sua proposta governamental era debatida com a população participante. Depois de discutir, priorizar e votar as políticas públicas propostas pelo governo, os participantes as defendiam, reconhecendo nelas a sua influência e, ao fim, garantiam a legitimidade necessária para o governo implantá-las. As assembléias do OP-RS serviam, assim, para politizar determinados temas e programas que dificilmente seriam colocados em prática se não tivessem o respaldo popular. Mas, se esta era uma forte motivação para a implantação do OP-RS, ela não era a única dado o compromisso histórico do Partido dos Trabalhadores com a participação na gestão pública. Este compromisso sempre foi parte do repertório discursivo e prático das gestões petistas e foi

\footnotetext{
25 Para uma discussão sobre a qualidade democrática da representação, ver Urbinati (2006).
} 
mantido pelo governo Dutra apesar dos riscos de implementar uma política participativa em um contexto substantivamente mais complexo. A gestão de Olívio Dutra foi, inclusive, a única a levar tal prática até o fim, em que pese as promessas feitas, na mesma ocasião, pelos governos do Mato Grosso do Sul, do Rio de Janeiro e de Minas Gerais.

A fim de conferir a validade da proposta orçamentária elaborada nestes fóruns e atender um outro público que não aquele que participava do $\mathrm{OP}$, os deputados da oposição implantaram um outro processo participativo de verificação desta proposta. Buscava-se, assim, contemplar um outro setor e legitimar as possíveis emendas efetuadas. Com isso, criou-se uma onda participativa no estado, movimentando-o durante todo o ano em torno das questões orçamentárias. Ambos, executivo e legislativo estaduais, buscavam respaldo popular para suas propostas, aproximando, então, as elites políticas estaduais da população gaúcha.

Esta participação acabou por conferir, em um cenário adverso para o executivo estadual, governabilidade à sua proposta de gestão pública, dado que discutida com a população e por ela referendada via votação. $\mathrm{O}$ legislativo e as outras lideranças estaduais não vinculadas ao OP.RS conseguiam, através do fórum democrático, polemizar e, por vezes, aperfeiçoar parte desta proposta.

No caso do legislativo estadual, a dinâmica impulsionada pelos fóruns levou seus representantes a se interiorizarem, os aproximando, segundo depoimento dos presidentes da ALRS, de seus representados em todo o estado. Os deputados passaram a percorrer todas as regiões do estado com as caravanas do fórum democrático. As audiências promovidas pelo fórum abriram oportunidades de debate sobre o projeto orçamentário confeccionado no âmbito do executivo. Deputados, representantes dos executivos e população participante debatiam a qualidade deste projeto e propunham emendas orçamentárias. Uma prática comum aos gabinetes dos deputados tornou-se pública. Para debater a proposta orçamentária gestada junto com a população que participava do OP, contrapô-la e/ou legitimar suas possíveis emendas orçamentárias, os deputados tinham que disponibilizar informações, fazer defesas públicas, organizar suas bases e discutir publicamente com o governo, que também participava destas audiências. Esta dinâmica abriu mais uma oportunidade para que seus participantes se aproximassem de seus representantes, ganhando mais aliados, tanto no executivo quanto no legislativo.

As dimensões participativa e pública valorizadas pela teoria democrática deliberativa e implementadas pelo OP estadual ampliaram, assim, as possibilidades de participação, publicização e controle dos poderes constituídos neste estado.

Retomando os três pontos da análise realizada sobre a validade da democracia deliberativa, dos fóruns e da publicização que eles promovem - o componente simbólico da publicização e o constrangimento que eles imputam à ação auto-interessada dos atores (ELSTER, 1999), a publicização e a discussão de novos 
FARIA, C. F. Fóruns participativos, controle democrático e a qualidade da democracia...

elementos contidos em uma determinada política que contribui para ampliar o grau de informação daqueles envolvidos no processo de decisão (DRYZECK, 2000) e o controle público - horizontal e vertical - exercido sobre a agenda política estabelecida (SMULOVITZ e PERUZZOTTI, 2000) - à luz dos acontencimentos relatados no Rio Grande do Sul na gestão Dutra após a implantação dos fóruns participativos, é possível dimensionar as contribuições destas inovações para a democracia neste estado.

Como vimos, a introdução dos fóruns do OP estadual e das audiências públicas promovidas pelo fórum democrático impactou positivamente tanto a conduta dos legisladores quanto dos representantes do executivo. Os legisladores, informados pelos debates nas audiências, passaram a ter maior respaldo popular para emendar ou vetar os projetos do executivo, ao passo que este, embora apoiado pela vontade dos cidadãos que participavam do OP, precisava renegociar as propostas mais polêmicas no segundo turno de rodadas participativas promovida pelo fórum. Exemplos desta dinâmica se encontram nos casos sobre a mudança na matriz tributária e da implantação da universidade estadual. Nos dois casos, os fóruns permitiram que a população participante apoderasse-se do conteúdo da matéria discutida, colocasse em xeque determinadas posições de seus representantes e se aliasse a eles à medida em que percebiam argumentos razoáveis de cada uma das partes.

Desta forma, os fóruns impulsionaram uma dinâmica virtuosa entre representação e participação dos cidadãos através da qual eles passaram a contar não só com a possibilidade de decidir diretamente sobre as políticas públicas de seus interesses, como também viram suas decisões fiscalizadas e, por vezes, aprimoradas pelos legisladores. Neste caso, a dinâmica que redundou na implantação da universidade estadual é um exemplo paradigmático pois possibilitou a construção de decisões que envolveram e contemplaram os diveros setores da população gaúcha, gerando, mediante o confronto estabelecido, mais recursos informacionais e diminuindo, conseqüentemente, os custos da participação para os setores interessados.

Além de aprimorarem os mecanismos horizontais e verticais de controle democrático no estado, os fóruns interpuseram-se às tradicionais relações entre executivo estadual, executivo municipal e legislativo à medida em que parte das negociações sobre os recursos orçamentários passaram a ocorrer publicamente. Deve-se a este fato a adesão dos prefeitos às plenárias do OP-RS, embora nem sempre de forma voluntária.

Se, por um lado, este novo padrão de relação produziu condições de governabilidade ao governo Dutra e reforçou o papel de fiscalizador do parlamento estadual, ele promoveu também uma rede de oposição significativa que, com certeza, 
ajudou a viabilizar a derrota do candidato do Partido dos Trabalhadores nas eleições de $2002^{26}$.

Esta derrota pôs fim aos fóruns impulsionados pelo OP-RS embora não tenha acabado com as formas participativas de discussão orçamentária. O governo Germano Rigotto (2002-2006) implantou uma outra proposta, a consulta popular, baseada em uma dinâmica participativa mais indireta, organizada pelos conselhos municipais, regionais e estaduais existentes. Como a tradição política do estado manda, está em disputa, novamente, o melhor desenho que viabilizará não só uma maior inclusão política dos seus cidadãos como uma relação mais transparente e equilibrada entre os poderes no Rio Grande do Sul.

\section{Referências Bibliográficas}

ABRANCHES, S. H. Presidencialismo de coalizão: o dilema institucional brasileiro. Dados Revista de Ciências Sociais, v. 31, n. 1, p. 5-34, 1988.

ABRÚCIO, F. L. Os barões da Federação. Os governadores e a redemocratização brasileira. São Paulo: Editora Hucitec. Departamento de Ciência Política, USP, 1998.

ANASTASIA, F.; MELO, C. R. Accountability, representação e estabilidade política no Brasil. In: ABRÚCIO, F.; LOUREIRO, M. A. (orgs.). O Estado numa era de reformas: os anos FHC. São Paulo: FGV, 2004.

ASSEMBLÉIA DO RIO GRANDE DO SUL. Legislando. 2001. Fórum Democrático. www.al.rs.gov.br.

AVRITZER, L. Sociedade civil, espaço público e poder local: uma análise do Orçamento Participativo em Belo Horizonte e Porto Alegre. In: DAGNINO, E. (org.). Sociedade civil e espaços públicos no Brasil. Rio de Janeiro: Paz e Terra, 2002.

\footnotetext{
26 Esta não foi a única razão da derrota do PT nas eleições, problemas internos ao partido também comprometeram sua viabilidade eleitoral. Mas, a polarização com a atual administração era constante, envolvendo a maioria das elites políticas e econômicas do estado, inclusive a RBS, principal empresa de comunicações no estado.
} 
FARIA, C. F. Fóruns participativos, controle democrático e a qualidade da democracia...

AVRITZER, L.; NAVARRO, Z. (orgs.). A inovação democrática no Brasil: o Orçamento Participativo. São Paulo: Ed. Cortez, 2003.

AVRITZER, L.; ANASTASIA, F. (orgs.). Reforma Política no Brasil. Belo Horizonte: Ed. da UFMG, 2006.

BAIERLE, S. G. Um novo princípio ético-político: prática social e sujeito nos movimentos populares urbanos em Porto Alegre nos anos 80. Campinas. 330 páginas. Dissertação (mestrado).

Unicamp, 1992.

BOHMAN, J. Deliberation public: pluralism, complexity and democracy. Cambridge: MIT Press, 1996.

COREDES-RS. Pró-RS - estratégicas regionais pró-desenvolvimento do RS. 1999.

CÔRTES, S. M. V. O Orçamento Participativo do Rio Grande do Sul: fortalecendo aliados regionais e construindo governabilidade - 1999 a 2002. 2004. (mimeo).

CRC/PMPA - CIDADE - Gianpaolo Baiocchi (University of Wisconsin). Quem é o público do OP $-1998.1998$.

DAHL, R. On democracy. Yale University Press, 2000.

DIAS, M. R. Sob o signo da vontade popular: o Orçamento Participativo e o dilema da Câmara Municipal de Porto Alegre. Belo Horizonte: Ed. da UFMG, 2002.

DRYZEK, J. S. Deliberative democracy and beyond. Oxford University Press, 2000.

ELSTER. J. (ed.). Deliberative democracy. Cambridge University Press, 1998.

FARIA, C. F. Democratizando a relação entre o poder público municipal e a sociedade civil: o Orçamento Participativo em Belo Horizonte. Belo Horizonte. 220 páginas. Dissertação (mestrado). Departamento de Ciência Política - UFMG, 1996.

Considerações sobre a dinâmica, a implementação e os atores do OP-RS. Relatório de Pesquisa, 2002. 
O que a estadualização da participação tem a dizer sobre a prática deliberativa: uma análise do Orçamento Participativo no Rio Grande do Sul (1999-2002). Paper apresentado no $5^{\circ}$. Encontro da ABCP. 2006. (mimeo)

FEDOZZI, L. Orçamento Participativo: reflexões sobre a experiência de Porto Alegre. Porto Alegre: Tomo Editorial, 1999.

FIGUEIREDO, A. C.; LIMONGI, F. Executivo e legislativo na nova ordem constitucional. São Paulo: Ed. FGV, 1999.

GOVERNO DO ESTADO DO RIO GRANDE DO SUL. Secretaria da Coordenação e Planejamento. Consulta Popular. 1998.

. Orçamento Participativo. Regimento interno: critérios e metodologia. 2000.

. Orçamento Participativo. Prioridades do Estado. Temática de desenvolvimento e obras e serviços. 2001.

. Orçamento Participativo. Orientações para propostas, debates e votações nas assembléias 2001. 2001 2002. 2001.

Orçamento Participativo. O processo em 2001. Para elaborar o Orçamento Estadual de . Orçamento Participativo. 2001. www.estado.rs.gov.br.

Secretaria da Educação. Universidade Estadual-RS. 2001.

Orçamento Participativo. Construção de uma nova matriz tributária de investimentos e salarial. 2001.

GROHMANN, L. G. O Processo legislativo no Rio Grande do Sul: 1995 a 1998. In: SANTOS, F. (org.). O poder legislativo nos estados: diversidade e convergência. Rio de Janeiro: Ed. FGV, 2001.

HABERMAS, J. Between facts and norms. Cambridge, MIT Press, 1996.

JORNAL ZERO HORA. RBS. 1999-2002. 
FARIA, C. F. Fóruns participativos, controle democrático e a qualidade da democracia...

MARQUES, L. (org.). Rio Grande do Sul: Estado e cidadania. Porto Alegre: Palmarinca, 1999.

MARQUETTI, A. Participação e redistribuição: o Orçamento Participativo em Porto Alegre. In: AVRITZER, L.; NAVARRO, Z. (orgs.). A inovação democrática no Brasil: o Orçamento Participativo. São Paulo: Ed. Cortez, 2003.

MELO, M. A. Instituições orçamentárias municipais e o processo legislativo em Recife - 1998 . 2000. In: LUBAMBO, C.; COÊLHO, D. B.; MELO, M. A. (orgs.). Desenho institucional e participação política: experiências no Brasil contemporâneo. Petrópolis: Ed. Vozes, 2005.

NAVARRO, Z. Affirmative democracy and redistributive development: the case of participatory budgeting in Porto Alegre, Brazil. Washington:World Bank Report, 1998. (mimeo)

PROGRAMA DE GOVERNO DA FRENTE POPULAR. Texto para Discussão, 1998.

PRZEWORSKI, A; STOKES, S.; MANIN, B. Democracy, accountability and representation. Cambridge University Press, 1999.

SANTOS, F. Patronagem e poder de agenda na política brasileira. Dados - Revista de Ciências Sociais, v. 40, n. 3, p. 465-92, 1997.

SCHMIDT, C.; HERRLEIN Jr. Os dois projetos contemporâneos de desenvolvimento para o Rio Grande do Sul. Porto Alegre: FAPERGS. Relatório de Pesquisa, 2003.

SCHNEIDER, A.; GOLDFRANK, B. Construção institucional competitiva: o PT e o Orçamento Participativo no Rio Grande do Sul. In: LUBAMBO, C.; COÊLHO, D. B.; MELO, M. A. (orgs.). Desenho institucional e participação política: experiências no Brasil contemporâneo. Petrópolis: Ed. Vozes, 2005.

SILVA, M. K. Construção da "participação popular": análise comparativa de processos de participação social na discussão pública do orçamento em municípios da Região Metropolitana de Porto Alegre/RS. Porto Alegre. 380 páginas. Tese (doutorado). Departamento de Sociologia da UFRGS, 2001.

SMULOVITZ, C.; PERUZZOTTI, H. Societal Accountability in Latin America. Journal of Democracy, v. 11, n. 4, p. 147-158, 2000.

SOUZA SANTOS, B. Participatory budgeting in Porto Alegre: toward a redistributive democracy. Politics \& Society, v. 26, n. 4, p. 461-510, 1998. 
SOUZA, U. Orçamento Participativo - experiência do Rio Grande do Sul. 1999. (mimeo)

WAMPLER, B. Instituições, associações e interesses no orçamento participativo de São Paulo. In: AVRITZER, L. (org.). A participação em São Paulo. SP: Ed. UNESP, 2004.

URBINATI, N. O que torna a representação democrática? Revista Lua Nova, n. 67, p. 191-228, 2006.

Recebido para publicação em junho de 2006. Aprovado para publicação em agosto de 2006. 